NORTH

AMERICAN

PRIMARY CARE From the North American
RESEARCH

RESEARCH

Primary Care Research Group

Ann Fam Med 2011;9:376. doi:10.1370/afm.1282.

\section{FROM NAPCRG TO WHOPPER?}

At the NAPCRG meeting in 2010 there was some discussion that perhaps the first part of the acronym, North American, was too restrictive. Hallway conversations in foreign languages such as Portuguese and Dutch (I could only understand half of what they said) suggested more than North Americans were in attendance.

What should the new name be? Perhaps the Worldwide Health Organization for Premier Primary care Excellence in Research (WHOPPER).

Maybe not.

A more quantitative approach suggests my hallway qualitative data collection at the NAPCRG meeting had merit. International members of NAPCRG numbered 54 in 2000 and represented $8 \%$ of the total. As NAPCRG grew in North America in the 2000s, international interest grew slightly faster, comprising $10 \%$ of the membership in the late 2000s. Growth in international members' meeting attendance increased faster, from $8 \%$ in 2000 to $15 \%$ in the late 2000 s. The countries with the largest attendance in 2010 were the United Kingdom (38), Australia (17), and Portugal (17). There was also a large Dutch contingent at the 2009 meeting in Montreal.

The meetings in Vancouver (2007) and Puerto Rico (2008) were the largest in NAPCRG's history, and international members were a big part of that success. At Vancouver in particular there were 122 attendees from outside Canada and the United States.

Overall, NAPCRG membership is nearing 1,000 (666 in 2000 to 995 in 2010). The most robust recent growth has been from researchers in training, which grew from 45 in 2000 to 353 in 2010. Some of these new colleagues are from countries as far away as Australia, Singapore, and the Netherlands.

European researchers add richness and depth to NAPCRG meetings with their strong primary care infrastructure and tradition. They are also able to complete studies of large populations of primary care patients with a depth American researchers could only dream of. Their publishing successes have made important contributions to the maturation of primary care worldwide.

Their presence is helping NAPCRG to become the leading international primary care research organiza- tion and annual meeting in the world. The findings of members' research help family physicians and general practitioners deliver better health care and improve the health of their patients back in their communities.

I suppose we need a new acronym that demonstrates the positive impact of NAPCRG members on the health of all the citizens of the world. How about Global Research Enables Amazing Transformation (GREAT)?

Mabye not. I'll keep trying.

Richard A. Young, MD

Director of Research and Co-Associate Program Director Jobn Peter Smith Hospital Family Medicine Residency Program

Fort Worth, Texas

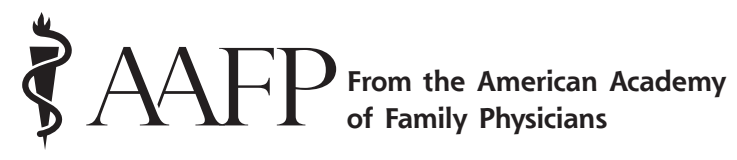

Ann Fam Med 2011;9:376-377. doi:10.1370/afm.1284.

\section{AAFP PRESIDENT GOES TO CAPITOL HILL TO PROPOSE BLENDED PAYMENT MODEL TO FIX MEDICARE PAYMENT SYSTEM}

The AAFP has been working with Congressional representatives and the other primary care physician associations for years in an attempt to fix the Medicare payment system for family physicians. The sustainable growth rate (SGR) system that is used currently to determine payments for Medicare physicians has resulted in drastic cuts to physician pay during the past few years. Those cuts have always been alleviated by Congressional action, but the AAFP continues to call on Congress to revamp the payment system.

On May 5, the AAFP once again took its message to Capitol Hill, but this time the Academy was invited to testify before a House panel about alternatives to the SGR formula.

AAFP President Roland Goertz, MD, MBA, of Waco, Texas, told the health subcommittee of the Energy and Commerce Committee, during a hearing on Capitol Hill that Congress has to enact a Medicare physician payment system that provides greater support for team-based primary care and the patientcentered medical home (PCMH) through a blended payment model,

"Congress, understandably, is most concerned with controlling federal expenditures for health care, especially given the rapidly rising costs for Medicare," said Goertz during his testimony. However, "There is growing and compelling evidence that a health care system based on primary care will help control 
these costs, as well as increase patient satisfaction and improve patient health.

"Simply reforming the fee-for-service system, which undervalues preventive health and team care coordination, cannot produce the results that Congress and patients require," said Goertz. He proposed a blended payment model that contains 3 elements:

- some fee-for-service payments

- a care coordination fee that compensates physicians for their expertise and the time required for primary care activities, which are not paid for currently

- performance bonuses based on a voluntary payfor-reporting/performance system, and for care team members and services that are not eligible for fee-for-service billing

Acknowledging that it will take time to transition to a blended payment model, Goertz, called for a 5 -year transition period with mandated payment updates that incorporate higher rates of at least $2 \%$ for primary care physicians for Medicare fee-for-service payments.

In addition, he noted, Congress should continue to pay the primary care incentive payment for primary care services called for by the Patient Protection and Affordable Care Act, but it should increase that incentive payment from $10 \%-20 \%$. Congress also needs to permanently extend the program that equalizes Medicaid and Medicare payment rates, Goertz said.

"Both of these programs, along with mandated updates that are $2 \%$ higher for primary care physicians, will help stabilize current (medical) practices that have seen such financial turmoil in the past few years," said Goertz.

During this proposed 5-year period, it also will be crucial to encourage as much innovation as possible, said Goertz. "The new CMS Center for (Medicare and Medicaid) Innovation needs to be a key focus of this effort. We believe this center can help CMS create market-based, private sector-like programs that can significantly bend the health care cost curve."

The SGR formula has repeatedly called for cuts in Medicare payments to physicians during the past few years. In 2010, Congress intervened 5 times to block impending Medicare payment cuts mandated by the SGR. Without further Congressional intervention, physicians face a cut of $29.4 \%$ on January 1 .

The SGR formula threatens the stability of the Medicare system for both patients and physicians, said lawmakers during the hearing.

The SGR is symptomatic of a "fundamentally flawed payment system," said Rep. Joe Pitts, R-Pa., chair of the subcommittee. "Keeping the current system or making minor adjustments is no longer a viable option."
Congress needs to "work toward a new way of paying for care, for physicians and all providers, that encourages integrated care," noted subcommittee member Rep. Henry Waxman, D-Calif.

The PCMH is an excellent example of an integrated care model that uses a team-based approach to deliver patient-centered care, said Goertz during a question-and-answer session, adding, "There are more than enough demonstrations that already show the benefit (of the medical home)."

Subcommittee member Rep. Tammy Baldwin, D-Wis., also touted the benefits of the PCMH. She described the experience of Dean Health Systems, an integrated health system in her district that has significantly improved care and reduced costs by adopting the medical home model. The health system developed its own payment system to support the PCMH model because of the limitations of the fee-for-service system, said Baldwin.

Developing a medical home where a practice-based care team takes collective responsibility for a patient's ongoing care, "would not have been possible within the (current) fee-for-service construct," said Baldwin.

James Arvantes

Wasbington Correspondent AAFP News Now

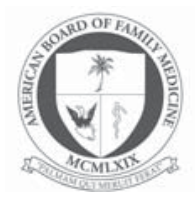

From the American Board of Family Medicine

Ann Fam Med 2011;9:377-378. doi:10.1370/afm.1280.

\section{AMERICAN BOARD OF FAMILY MEDICINE ELECTS NEW OFFICERS AND BOARD MEMBERS}

The American Board of Family Medicine (ABFM) is pleased to announce the election of 4 new officers and 3 new board members. The new officers elected at the ABFM's spring board meeting in April 2011 are: Warren P. Newton, MD of Chapel Hill, North Carolina, elected as Chair; Samuel Jones, MD of Fairfax, Virginia as Chair Elect; Arlene Brown, MD of Ruidoso, New Mexico as Treasurer; and Michael Workings, MD of Detroit, Michigan as Member-at-Large, Executive Committee. In addition, the ABFM welcomes this year's new members to the Board of Directors: Laura M. Brooks, MD of Lynchburg, Virginia ${ }_{i}$ James Kennedy, MD of Winter Park, Colorado; and Stanley Kozakowski, MD of Milford, New Jersey. 